\title{
IMPLEMENTASI HADIS-HADIS SABAR DALAM MENGHADAPI BENCANA (Studi Kasus Bencana Banjir di Kepatihan Jember)
}

\author{
Irfan Yuhadi \\ Program Studi Ilmu Hadits \\ Sekolah Tinggi Dirasat Islamiyah Imam Syafi’i Jember \\ irfan.yuhadi@stdiis.ac.id \\ Nurul Budi Murtini \\ Program Studi Ilmu Hadits \\ Sekolah Tinggi Dirasat Islamiyah Imam Syafi'i Jember \\ nurulb@stdiis.ac.id
}

\begin{abstract}
In human life, it always revolves between happiness and sadness, ease and difficulty, even life and death. All the calamities that occur have been determined by Allah in the Lawh al-Mahfuz. Not a single disaster befell someone except with the permission of Allah. Allah will give guidance to the heart of believers to be patient in accepting calamities. Jember Regency consists of 226 villages, 22 subdistricts, and 31 districts, among which is Kepatihan subdistrict. In February 2021, there were floods in Jember, among the areas affected was Kepatihan. The purpose of this research is to analyze and to find the redaction of hadiths about patience, the phenomenon of the flood in Kepatihan Jember, and the implementation of the hadiths about patience in dealing with floods in Kepatihan Jember. The approach in this research is a qualitative approach with a type of case studies. The results of this study indicate that: (1) There are several redactions of hadith about patience, among them are: hadith from Abu Malik AlAsy'ari, hadith from Anas, hadith from 'Ubadah bin Ash-Shamit, hadith from Abu Sa'id AlKhudri, and hadith from Shuhaib - may Allah be pleased with them. (2) In Kepatihan Jember, 32 families were affected by the flood, among the worst were 8 houses. (3) The residents of Kepatihan Jember have implemented the hadiths of patience in facing the flood disaster that occurred in February 2021.
\end{abstract}

Keywords: Implementation of Hadits, Hadith About Patience, Flood Disaster.

\begin{abstract}
ABSTRAK
Dalam kehidupan manusia selalu berputar antara kebahagian dengan kesedihan, kemudahan dengan kesulitan, bahkan kehidupan dengan kematian. Semua musibah yang terjadi telah ditetapkan oleh Allah di Lauh al-Mahfuzh. Tidak ada suatu musibah pun yang menimpa seseorang kecuali dengan izin Allah. Allah akan memberikan petunjuk kepada hati orang-orang yang beriman untuk bersabar dalam menerima musibah. Kabupaten Jember terdiri 226 desa, 22
\end{abstract}


kelurahan dan 31 kecamatan, di antara adalah kelurahan Kepatihan. Pada bulan Februari 2021 terjadi banjir di Jember, di antara wilayah yang terkena dampaknya adalah Kepatihan. Tujuan dari penelitian ini adalah menganalisis dan menemukan redaksi hadis-hadis tentang sabar, fenomena bencana banjir di Kepatihan Jember dan implementasi hadis-hadis sabar dalam menghadapi bencana banjir di Kepatihan Jember. Pendekatan dalam penelitian ini adalah dengan menggunakan pendekatan kualitatif dengan jenis studi kasus. Hasil dari penelitian ini menunjukkan bahwa: (1) Terdapat beberapa redaksi hadis tentang sabar, di antaranya adalah hadis dari Abu Malik Al-Asy'ari, hadis dari Anas, hadis dari 'Ubadah bin Ash-Shamit, hadis dari Abu Sa'id Al-Khudri, dan hadis dari Shuhaib radhiyallahu 'anhum. (2) Di Kepatihan Jember terdapat $32 \mathrm{KK}$ yang terdampak banjir, yang parah ada 8 rumah. (3) Warga Kepatihan Jember telah mengimplemantasikan hadis-hadis sabar dalam menghadapi bencana banjir yang terjadi di bulan Februari 2021.

Kata Kunci: Implementasi Hadis, Hadis Sabar, Bencana Banjir.

\section{A. PENDAHULUAN}

Dalam kehidupan manusia selalu berputar antara kebahagian dengan kesedihan, kemudahan dengan kesulitan, bahkan kehidupan dengan kematian. Allah Subhanahu wa Ta'ala menguji manusia dengan ketakutan, kekurangan harta dan dengan kematian. Allah Subhanahu wa Ta'ala berfirman;

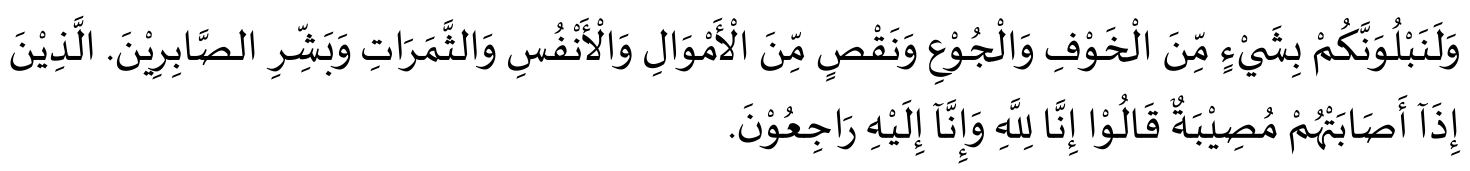

Sungguh akan Kami berikan cobaan kepada kalian dengan sedikit ketakutan, kelaparan, kekurangan, harta, jiwa dan buah-buahan. Berikanlah berita gembira kepada orang-orang yang sabar. (Yaitu) orang-orang yang apabila ditimpa musibah mereka mengucapkan, "Sesungguhnya kami adalah milik Allah dan kepada-Nya kami kembali. (QS. Al-Baqarah: 155 - 156)

Semua musibah yang terjadi telah ditetapkan oleh Allah di Lauh al-Mahfuzh. Allah Subhanahu wa Ta'ala berfirman; 


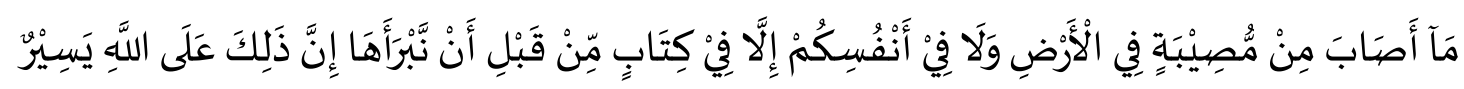

Tidak ada suatu bencana pun yang terjadi di bumi dan (tidak pula) pada diri kalian melainkan telah tertulis dalam kitab (Lauh al-Mahfuzh) sebelum Kami menciptakannya. Sesungguhnya yang demikian itu adalah mudah bagi Allah. (QS. Al-Hadid: 22)

Musibah yang terjadi disebabkan karena perbuatan dosa-dosa manusia. Allah Subhanahu wa Ta'ala berfirman;

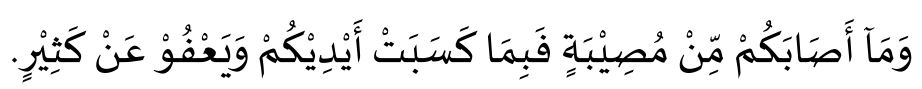

Apapun musibah yang menimpa kalian, maka itu disebabkan karena perbuatan tangan kalian sendiri dan Allah memaafkan sebagian besar (kesalahan kalian). (QS. AsySyura: 30)

Tidak ada suatu musibah pun yang menimpa seseorang kecuali dengan izin Allah. Allah akan memberikan petunjuk kepada hati orang-orang yang beriman untuk bersabar dalam menerima musibah (Al-Suyuthi, 1422: 568). Allah Subhanahu wa Ta'ala berfirman;

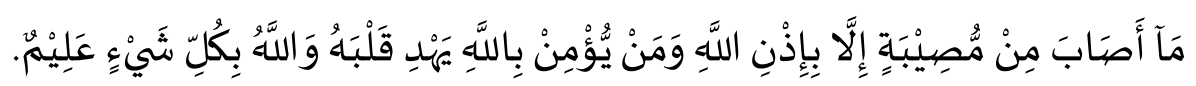

Tidak ada suatu musibah pun yang menimpa seseorang kecuali dengan izin Allah. Barangsiapa yang beriman kepada Allah, niscaya Allah akan memberikan petunjuk kepada hatinya. Allah Maha Mengetahui segala sesuatu. (QS. At-Taghabun: 30)

Allah memerintahkan orang-orang yang beriman agar menjadikan sabar sebagai penolong. Allah Subhanahu wa Ta'ala berfirman; 


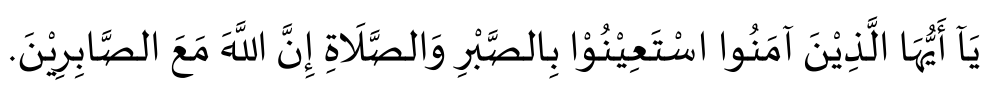

Wahai orang-orang yang beriman, jadikanlah sabar dan shalat sebagai penolong kalian, sesungguhnya Allah bersama orang-orang yang sabar. (QS. Al-Baqarah: 153)

Allah telah menyebutkan kata "sabar" pada sembilan puluh tempat dalam Al-Qur'an (al-Ghurasi, 2010: 174). Asal kata sabar adalah al-man'u (mencegah) dan al-habsu (menahan). Sehingga yang dimaksud dengan sabar adalah menahan jiwa dari gelisah, menahan lisan dari mengeluh, menahan anggota badan dari menampar pipi, merobek baju, dan yang semisalnya (Al-Jauziyah, 1426: 14). Sabar mencakup tiga hal, sebagaimana penjelasan Syaikh Muhammmad bin Shalih Al-'Utsaimin Rahimahullah;

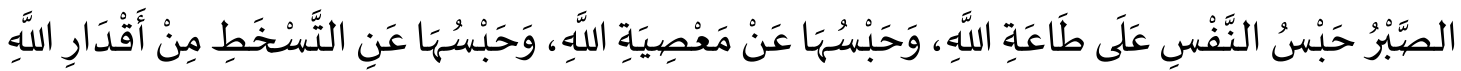

Sabar adalah (1) menahan diri dalam (menjauhi hal-hal yang dapat menghalangi untuk) melaksanakan perintah Allah, (2) menahan diri dalam meninggalkan maksiat kepada Allah, dan (3) menahan diri dari marah terhadap takdir Allah. (Al-'Utsaimin, 1427: 14)

Ketika seorang hamba mampu bersabar terhadap suatu nikmat yang dicabut oleh Allah, maka Allah akan menggantikannya dengan sesuatu yang lebih baik. Sabar merupakan sebaikbaik pemberian, karena ia selalu berhubungan dengan segala urusan seorang hamba. Segala keadaan seorang hamba pasti memerlukan kesabaran. Sabar pada awalnya sangat berat dirasakan. Namun pada akhirnya ia menjadi mudah dan baik akibatnya. Seperti yang dikatakan seorang penyair;

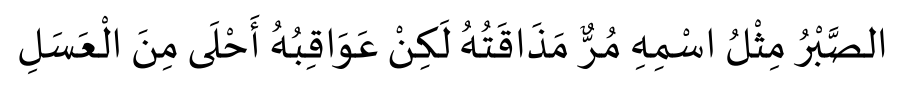

Sabar itu seperti namanya. Ia sangat pahit rasanya, tetapi akibatnya lebih manis daripada madu. (Al-Sa'di, 2016: 144) 
Wilayah Kabupaten Jember mencakup area seluas 3.293,34 $\mathrm{Km}^{2}$, dengan karakter topografi dataran ngarai yang subur pada bagian tengah dan selatan. Iklim di Kabupaten Jember adalah iklim tropis. Musim kemarau biasa terjadi pada bulan Mei sampai bulan Agustus dan musim hujan terjadi pada bulan September sampai bulan Januari. Sedangkan curah hujan cukup banyak berkisar antara $1.969 \mathrm{~mm}$ sampai $3.394 \mathrm{~mm}$. Kabupaten Jember memiliki beberapa sungai antara lain Sungai Bedadung yang bersumber dari Pegunungan Iyang di bagian Tengah, Sungai Mayang yang bersumber dari Pegunungan Raung di bagian timur, dan Sungai Bondoyudo yang bersumber dari Pegunungan Semeru di bagian barat.

Kabupaten Jember terdiri 226 desa, 22 kelurahan dan 31 kecamatan. Di antara adalah: kecamatan Ajung, Ambulu, Arjasa, Bangsalsari, Gumukmas, Jelbuk, Jenggawah, Kalisat, Kaliwates, Kencong, Mumbulsari, Rambipuji, Sumbersari, Tanggul dan Wuluhan. Penduduk kecamatan Kaliwates sebanyak 110.009 jiwa terdiri dari 52.018 laki-laki dan 57.991 perempuan yang tersebar di 7 kelurahan, antara lain: kelurahan Mangli, Kebon Agung, Kaliwates, Tegal Besar, Sempusari, Jember Kidul dan Kepatihan (https://id.wikipedia.org/wiki/Kaliwates, Diakses tanggal 05 Maret 2021). Kelurahan Kepatihan terdiri dari lingkungan: Kauman, Kebon Dalem, Sawahan Cantikan, Tembaan dan Kepatihan.

Pada bulan Februari 2021 terjadi banjir di Jember, di antara wilayah yang terkena dampaknya adalah Kepatihan. Peneliti melihat beberapa rumah yang berada di daerah Kepatihan Jember hancur akibat diterjang banjir. Fenomena ini menarik peneliti untuk menelusuri lebih jauh tentang implementasi hadis-hadis sabar dalam menghadapi bencana banjir di Kepatihan Jember.

Dari hasil penelusuran dari berbagai penelitian terdahulu, sejauh ini belum ditemukan adanya kajian tentang implementasi hadits-hadits sabar dalam menghadapi bencana dengan fokus pembahasan yang mengkaji tentang; redaksi hadis-hadis tentang sabar, fenomena bencana banjir di Kepatihan Jember dan implementasi hadis-hadis sabar dalam menghadapi bencana banjir di Kepatihan Jember. Adapun hasil penelusuran penelitian terdahulu adalah: M. Idman Salewe yang meneliti tentang "Sabar Dalam Hadis" (Salewe, 2018), Qurotul Uyun dan Rumiani yang meneliti tentang "Sabar dan Shalat Sebagai Model Untuk Meningkatkan Resiliensi di Daerah Bencana Yogyakarta” (Rumiani, 2012), Muhammad Alfatih Suryadilaga yang meneliti tentang "Pemahaman Hadis Tentang Bencana (Sebuah Kajian Teologis Terhadap Hadis-hadis Tentang Bencana)" (Suryadilaga, 2012), Wendi Parwanto yang meneliti tentang 
“Teologi Bencana Perspektif Hadis: Mendiskusikan antara yang Menghujat dan yang Moderat" (Parwanto, 2019), dan Arco Triady Ujung, Arief Laila Nugraha dan Hana Sugiastu Firdaus yang meneliti tentang "Kajian Pemetaan Risiko Bencana Banjir Kota Semarang Dengan Menggunakan Sistem Informasi Geografis” (Arco Triady Ujung, 2019).

Dari latar belakang di atas terdapat tiga rumusan masalah yang dikaji dalam penelitian ini, antara lain tentang: redaksi hadis-hadis tentang sabar, fenomena bencana banjir di Kepatihan Jember dan implementasi hadis-hadis sabar dalam menghadapi bencana banjir di Kepatihan Jember.

\section{B. METODE PENELITIAN}

Pendekatan yang digunakan dalam penelitian ini adalah pendekatan kualitatif. Pendekatan kualitatif bertujuan untuk memahami makna yang disimpulkan dalam perilaku masyarakat menurut perspektif masyarakat itu sendiri (Imam Suprayogo, 2003: 9). Penelitian ini menggunakan jenis penelitian studi kasus. Studi kasus dilakukan terhadap peristiwa atau gejala yang sedang berlangsung bukan gejala atau peristiwa yang telah berlangsung (ex post facto) (Rahardjo, 2012).

Dalam penelitian kualitatif peneliti merupakan perencana, pelaksana pengumpul data, penafsir data dan pada akhirnya ia menjadi pelapor hasil penelitian (Moelong, 2005: 174). Penelitian kualitatif merupakan pendekatan yang menekankan pada hasil pengamatan peneliti. Sehingga manusia sebagai instrumen penelitian menjadi suatu keharusan (Muhajir, 2003: 36). Bahkan dalam penelitian kualitaitf posisi peneliti menjadi instrumen kunci (the key instrument) (Sugiono, 2008: 223). Oleh karena itu, validitas dan reliabilitas data kualitatif banyak tergantung pada keterampilan metodologis, kepekaan dan integritas peneliti sendiri (Bagong Suyanto, 2007: 186). Sedangkan instrumen non manusia, seperti; wawancara, observasi maupun dokumentasi merupakan alat bantu dalam proses perekaman informasi (Moelong, 2005: 18).

Informan yang dipilih oleh peneliti adalah warga Kepatihan Jember yang terdampak banjir, dengan asumsi bahwa mereka adalah orang-orang yang mengetahui secara mendalam tentang rumusan masalah dalam penelitian ini. Data dikumpulkan dengan menggunakan teknik purposive sampling. Peneliti melakukan observasi, wawancara dan dokumentasi. Hal ini 
dilakukan oleh peneliti agar mendapatkan hasil yang komprehensif tentang rumusan masalah dalam penelitian ini.

\section{HASIL DAN PEMBAHASAN}

\section{Redaksi Hadis-hadis Tentang Sabar}

Terdapat beberapa redaksi hadis tentang sabar, di antaranya adalah:

a. Hadis dari Abu Malik Al-Asy'ari radhiyallahu 'anhu;

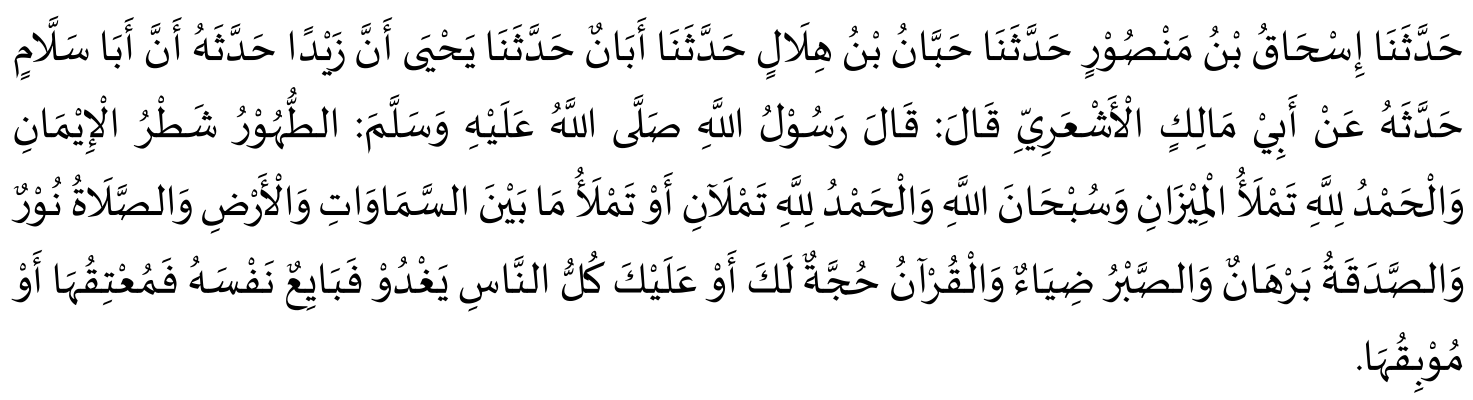

Telah menceritakan kepada kami Ishaq bin Manshur, telah menceritakan kepada kami Habban bin Hilal, telah menceritakan kepada kami Aban, telah menceritakan kepada kami Yahya, bahwa Zaid telah menceritakan kepadanya, bahwa Abu Sallam telah menceritakan kepadanya, dari Abu Malik Al-Asy'ari radhiyallahu 'anhu ia berkata, Rasulullah Shallallahu 'alaihi wa Sallam bersabda, "Bersuci adalah sebagian dari keimanan. (Bacaan) alhamdulillah (segala puji bagi Allah) memenuhi timbangan (amalan kebaikan). (Bacaan) subhanallah wal hamdulillah (Maha Suci Allah dan segala puji bagi Allah) memenuhi antara langit dan bumi. Shalat adalah cahaya. Sedekah adalah bukti. Sabar adalah cahaya. Al-Qur'an merupakan hujjah untukmu atau (hujjah) atasmu. Setiap manusia pergi menjual dirinya, ada yang membebaskan dirinya ada pula yang membinasakan dirinya." (Al-Naisaburi, 1437: 223)

Hadits ini menunjukkan bahwa sabar merupakan sifat terpuji yang menjadikan pelakunya memperoleh petunjuk untuk mendapatkan kebenaran. Di antara bentuk sabar adalah sabar ketika menghadapi musibah. 
b. Hadis dari Anas radhiyallahu 'anhu;

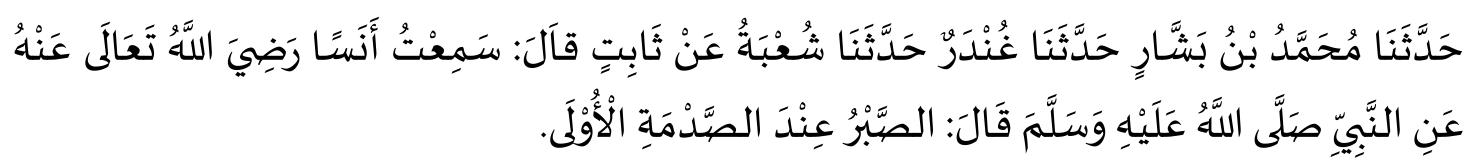

Telah menceritakan kepada kami Muhammad bin Basysyar, telah menceritakan kepada kami Ghundar, telah menceritakan kepada kami Syu'bah dari Tsabit ia berkata, aku mendengar Anas radhiyallahu ta'ala 'anhu, dari Nabi Shallallahu 'alaihi wa Sallam, beliau bersabda; "Kesabaran itu pada hentakan yang pertama." (Al-Bukhari, 1436: 1302)

Hadis ini menunjukkan anjuran untuk bersabar ketika awal mendapatkan musibah. Karena hakikat bersabar adalah pada saat awal mendapatkan musibah.

c. Hadis dari 'Ubadah bin Ash-Shamit radhiyallahu 'anhu;

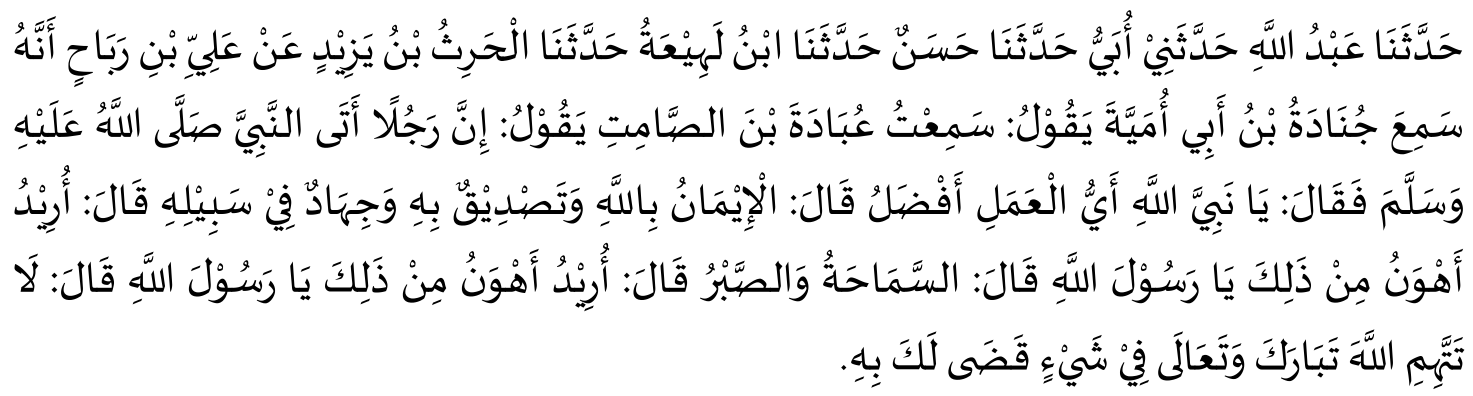

Telah menceritakan kepada kami 'Abdullah, telah menceritakan kepadaku Ubay, telah menceritakan kepada kami Hasan, telah menceritakan kepada kami Ibnu Lahi'ah, telah menceritakan kepada kami Al-Harits bin Yazid, dari 'Ali bin Rabah, bahwa ia mendengar Junadah bin Abi Umayyah berkata, aku mendengar 'Ubadah bin Shamith berkata, "Bahwa seorang laki-laki mendatangi Nabi Shallallahu 'alaihi wa Sallam dan bertanya, "Wahai Nabiyullah, amalan apakah yang paling utama?" Nabi Shallallahu 'alaihi wa Sallam bersabda, "Iman kepada Allah, membenarkan-Nya, dan berjihad di 
jalan-Nya." Laki-laki tersebut berkata, "Aku ingin yang lebih ringan dari itu, wahai Rasulullah.” Nabi Shallallahu 'alaihi wa Sallam bersabda, "Baik hati dan sabar.” Lakilaki tersebut (kembali) berkata, "Aku ingin yang lebih ringan dari itu, wahai Rasulullah." Nabi Shallallahu 'alaihi wa Sallam bersabda, "Janganlah engkau berburuk sangka kepada Allah Tabaraka wa Ta'ala terhadap suatu (musibah) yang telah ditetapkan-Nya kepadamu." (Al-Syaibani)

Hadis ini menunjukkan bahwa sabar merupakan salah satu amalan yang utama.

d. Hadis dari Abu Sa'id Al-Khudri radhiyallahu 'anhu;

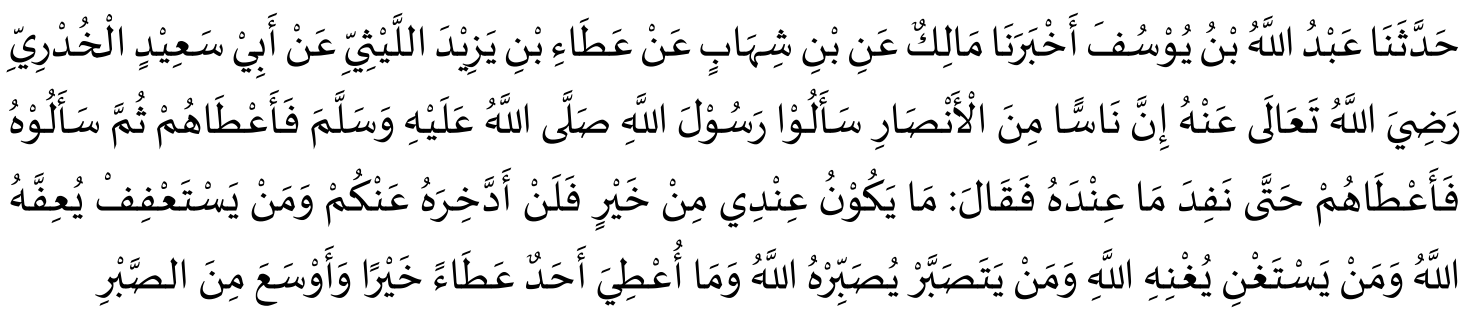

Telah menceritakan kepada kami 'Abdullah bin Yusuf, telah mengabarkan kepada kami Malik, dari Syihab, dari 'Atha' bin Yazid Al-Laitsi, dari Abu Sa'id Al-Khudri radhiyallahu ta'ala 'anhu, "Sesungguhnya beberapa orang Anshar meminta kepada Rasulullah Shallallahu 'alaihi wa Sallam, maka beliau memberi mereka. Kemudian mereka meminta kembali, maka beliau memberi mereka hingga habis apa yang ada di sisi beliau. Beliau bersabda, "Aku sudah tidak memiliki sesuatu pun dan aku tidak menyimpannya dari kalian. Barangsiapa yang berupaya menjaga kehormatannya, niscaya Allah akan menjaga kehormatannya. Barangsiapa yang merasa cukup, niscaya Allah Allah akan mencukupkannya. Barangsiapa melatih dirinya untuk bersabar, niscaya Allah akan menjadikannya penyabar. Tidaklah seseorang diberi karunia yang lebih baik dan lebih luas dibandingkan dengan kesabaran.” (Al-Bukhari, 1436: 1469)

Hadis ini menunjukkan bahwa sabar membutuhkan latihan dan pembiasaan. Ketika seseorang telah memiliki karakter penyabar, maka itu merupakan karunia yang besar dari Allah Subhanahu wa Ta'ala. 
e. Hadis dari Shuhaib radhiyallahu 'anhu;

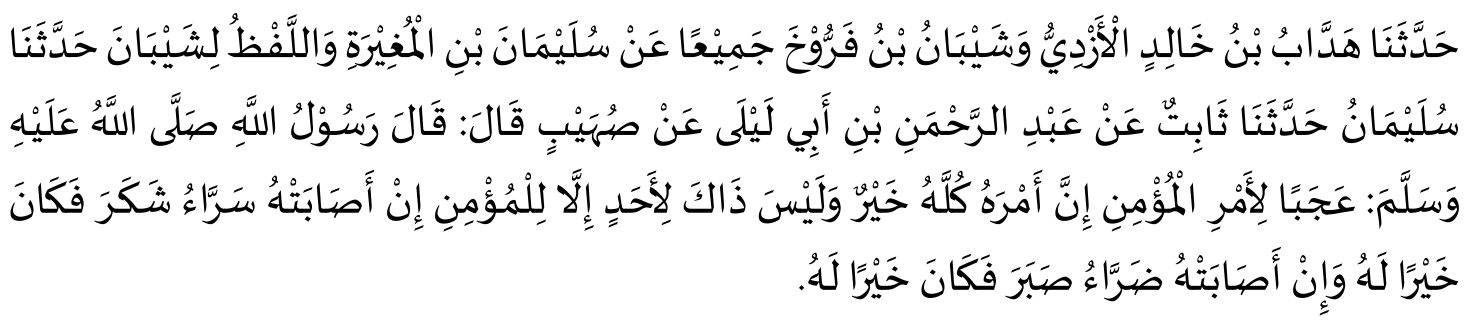

Telah menceritakan kepada kami Haddab bin Khalid Al-Azdi dan Syaiban bin Farukh, dari Sulaiman bin Al-Mughirah dan lafazh(nya) milik Syaiban, telah menceritakan kepada kami Sulaiman, telah menceritakan kepada kami Tsabit, dari 'Abdurrahman bin Abi Laila, dari Shuhaib radhiyallahu 'anhu ia berkata, Rasulullah Shallallahu 'alaihi wa Sallam bersabda; "Sungguh menakjubkan urusan orang yang beriman (karena) semua urusannya adalah baik (baginya). Yang demikian itu tidak dapat (melakukannya), kecuali orang yang beriman. Jika ia dikaruniai kesenangan ia bersyukur dan hal itu baik baginya. Jika ia ditimpa kesulitan ia bersabar dan hal itu baik baginya." (Al-Naisaburi, 1437: 2999)

Hadis ini menunjukkan bahwa sabar menjadi salah satu ciri karakter orang yang beriman, dengan kesabaran tersebut ia mendapatkan banyak kebaikan.

Dari penjelasan di atas dapat diketahui beberapa redaksi hadis tentang sabar, diantaranya adalah: hadis dari Abu Malik Al-Asy'ari, hadis dari Anas, hadis dari 'Ubadah bin Ash-Shamit, hadis dari Abu Sa'id Al-Khudri, dan hadis dari Shuhaib radhiyallahu 'anhum.

\section{Fenomena Bencana Banjir di Kepatihan Jember}

Banjir melanda 7 kecamatan di kabupaten Jember di bulan Februari 2021. Tujuh kecamatan yang terkena banjir adalah kecamatan; Rambipuji, Kaliwates, Sumbersari, Patrang, Pakusari, Kalisat, dan Jelbuk. Terdapat 77 rumah mengalami kerusakan akibat luapan sungai Bedadung. Dari 77 rumah rusak tersebut; 8 rumah rusak ringan, 42 rumah rusak sedang, dan 27 rumah rusak berat. Terdapat 411 Kepala Keluarga (KK) terdampak banjir yang tersebar di 13 desa/kelurahan di 7 kecamatan. 
Tercatat ada 7 lokasi yang terdampak bencana banjir akibat luapan Sungai Jompo dan tingginya curah hujan yang mengguyur wilayah setempat. Pertama, di kawasan Kreongan, kelurahan Jember Lor, kecamatan Patrang terdapat 77 rumah terendam air setinggi 10-60 cm. Kedua, di Jalan Kasuari, kelurahan Kedawung, kecamatan Patrang terdapat 12 rumah terendam air 30-50 cm dan 1 mushala terendam air, serta 1 rumah rusak ringan. Ketiga, di lingkungan Tempean, Desa Rambipuji, kecamatan Rambipuji terdapat 21 rumah terendam air $10-20 \mathrm{~cm}$ dan 2 mushala terendam air. Keempat, Jalan Sunan Bonang kelurahan Jember Kidul, kecamatan Kaliwates terdapat 1 rumah terendam air $5-10 \mathrm{~cm}$.

Kelima, di lingkungan Kauman, kelurahan Kepatihan, kecamatan Kaliwates yang menyebabkan 1 rumah yang kamar belakang dan dapurnya ambrol. Keenam, di Desa Klungkung, kecamatan Sukorambi menyebabkan 1 jembatan penghubung sementara rusak berat, sehingga tidak bisa dilalui karena tergerus luapan air sungai yang cukup deras. Ketujuh, di Desa Sukorejo, kecamatan Bangsalsari tercatat 32 rumah terendam air 20-50 cm dan 1 mushala terendam air.

Di kelurahan Kepatihan kecamatan Kaliwates, air mulai naik setelah Maghrib dan terus naik hingga menuntut warga untuk meyelamatkan barang-barang mereka. Banjir yang terjadi ini merupakan banjir terbesar. Telah terjadi 5 kali banjir di daerah Kepatihan, yaitu; tahun 1993, tahun 2000, tahun 2008, tahun 2012 dan tahun 2021. Sebagaimana yang disampaikan oleh M. Sholeh, selaku Ketua RT.05/RW.026 Jalan Raden Patah XIX;

Ya, bisa dikatakan air bah. Begitu adzan maghrib (mulai) ada yang longsor, setelah selesai shalat maghrib saya pulang airnya sudah naik. Warga ketika itu panik, mereka mengambil barang-barangnya dibawa keluar duluan. Nggak ngira bahwa banjir akan sebesar itu. Malamnya warga langsung bersih-bersih dan belum beraktifitas sampai sekarang. Selama saya tinggal disini banjir terbesar itu 5 kali, ini banjir terbesar. Awalnya tahun 1993, selang 7 tahun (tahun 2000) banjir lagi, 8 tahun (tahun 2008) banjir lagi, lalu tahun 2012 dan (tahun 2021) ini yang terbesar. Dari sejak saya kecil baru kali ini yang terbesar banjirnya. (Sholeh, 09 Februari 2021)

Di Kepatihan terdapat 32 KK yang terdampak banjir, yang parah ada 8 rumah, salah satunya ada 1 rumah yang kamar belakang dan dapurnya ambrol. Sebagaimana penjelasan M. Sholeh yang menyampaikan bahwa; 
Yang terdampak banjir khusus RT 5 ada 32 KK. Tapi yang paling terdampak ada 8 rumah; ada yang sedang ada pula yang parah. Dari segi ekonomi untuk makan per harinya (mereka) tidak kesulitan sehingga tidak dinilai miskin. Mereka punya pekerjaan semua. (Sholeh, 09 Februari 2021)

Dari paparan di atas dapat disimpulkan bahwa di Kepatihan Jember terdapat $32 \mathrm{KK}$ yang terdampak banjir, yang parah ada 8 rumah, salah satunya ada 1 rumah yang kamar belakang dan dapurnya ambrol. Sejak tahun 1993 hingga 2021 telah terjadi 5 kali banjir dan banjir di bulan Februari 2021 merupakan banjir yang terbesar.

\section{Implementasi Hadis-Hadis Sabar dalam Menghadapi Bencana Banjir di Kepatihan Jember}

Saat terjadi banjir di bulan Februari 2021, warga Kepatihan Jember panik. Mereka tidak menyangka akan terjadi banjir besar. Ketua RT disana berusaha untuk menenangkan warga agar tidak panik dan mengajak agar mengembalikan semua urusan kepada Allah Subhanahu wa Ta'ala. M. Sholeh selaku ketua RT menjelaskan;

Waktu itu orang-orang panik, akhirnya saya sadarkan untuk kembalikan kepada Allah. Harta bisa dicari. Kalau Allah meridhoi, bisa dicari (lagi). Kuncinya lari ke Allah aman kita. (Ini) bukan kemauan kita, ada yang lebih berkuasa. Kita wajib menerima dan ridha. Teknologi secanggih apapun kalau Allah berkehendak tidak ada apa-apanya. (Sholeh, 09 Februari 2021)

Ketika awal mendapatkan musibah, maka saat itulah dituntut adanya kesabaran. Sebagaimana diriwayatkan dari Anas radhiyallahu ta'ala 'anhu, dari Nabi Shallallahu 'alaihi wa Sallam, beliau bersabda;

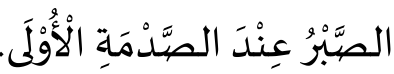

Kesabaran itu pada hentakan yang pertama. (Al-Bukhari, 1436: 1302) 
Tidak ada korban jiwa dalam bencana banjir di Kepatihan. Ini menyadarkan warga disana bahwa mereka masih beruntung. Karena hilangnya harta masih bisa dicari, berbeda dengan hilangnya nyawa. M. Sholeh menggambarkan upayanya untuk menenangkan warga Kepatihan, ia menyatakan;

Ketika air surut, seperti tidak punya harapan. Saya menenangkan orang-orang. Yang penting kamu sabar dan harus merasa beruntung. Karena jiwa tidak ada yang menjadi korban. Walau orang lain menganggapnya sebagai musibah, tapi saya menganggapnya sebagai ujian. Kalau musibah tentunya banyak korban jiwa, semua itu (hanya) titipan. (Sholeh, 09 Februari 2021)

Kesabaran membutuhkan latihan dan pembiasaan. Ketika seseorang telah memiliki karakter penyabar, maka itu merupakan karunia yang besar dari Allah Subhanahu wa Ta'ala. Diriwayatkan dari Abu Sa'id Al-Khudri radhiyallahu ta'ala 'anhu, Rasulullah Shallallahu 'alaihi wa Sallam bersabda,

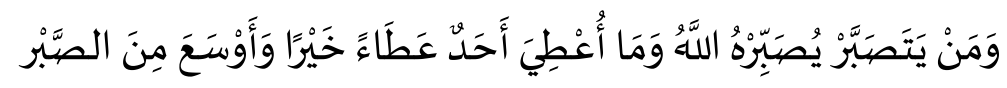

Barangsiapa melatih dirinya untuk bersabar, niscaya Allah akan menjadikannya penyabar. Tidaklah seseorang diberi karunia yang lebih baik dan lebih luas dibandingkan dengan kesabaran. (Al-Bukhari, 1436: 1469)

Para korban banjir di Kepatihan menyadari bahwa meskipun mereka menjadi korban bencana banjir, namun mereka menganggap masih beruntung karena banyak barang yang terselamatkan dan tidak ada korban jiwa dalam bencana banjir tersebut. M. Sholeh menjelaskan;

Yang terdampak banjir khusus RT 5 ada 32 KK. Tapi yang paling terdampak ada 8 rumah; ada yang sedang ada pula yang parah. Ada yang sok 1 orang. Sekarang orangnya di rumah saudaranya (untuk) menenangkan diri. Meskipun dapurnya habis tapi tetap bersyukur, harta semuanya milik Allah. Urusan harta Allah yang mengatur, keberkahan Allah yang mengatur. Tidak minta saja kita dikasih, apalagi minta. (Sholeh, 09 Februari 2021) 
Musibah dalam urusan dunia masih lebih ringan dibandingkan dengan musibah dalam urusan agama. Oleh karena itu, Rasulullah Shallallahu 'alaihi wa Sallam mengajarkan sebuah doa;

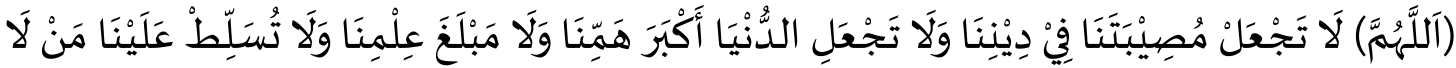

(Ya Allah), janganlah Engkau timpakan musibah dalam agama kami, janganlah Engkau jadikan dunia sebagai keinginan utama kami dan sebagai penghujung pengetahuan kami serta jangan pula Engkau jadikan orang-orang yang tidak menyayangi kami menguasai kami. (Al-Tirmidzi, 1439: 3502)

Sabar merupakan salah satu karakter orang yang beriman saat ditimpa kesulitan. Sebagaimana orang yang beriman akan bersyukur ketika mendapatkan kesenangan. Diriwayatkan dari Shuhaib radhiyallahu 'anhu ia berkata, Rasulullah Shallallahu 'alaihi wa Sallam bersabda;

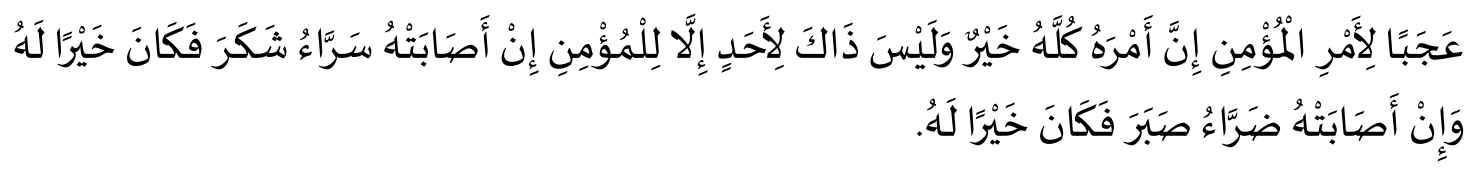

Sungguh menakjubkan urusan orang yang beriman (karena) semua urusannya adalah baik (baginya). Yang demikian itu tidak dapat (melakukannya), kecuali orang yang beriman. Jika ia dikaruniai kesenangan ia bersyukur dan hal itu baik baginya. Jika ia ditimpa kesulitan ia bersabar dan hal itu baik baginya. (Al-Naisaburi, 1437: 2999)

Setiap musibah yang menimpa seorang muslim sekecil apapun akan menjadi penghapus dosa-dosanya. Sebagaimana diriwayatkan dari Abu Hurairah radhiyallahu 'anhu, dari Nabi Shallallahu 'alaihi wa Sallam, beliau bersabda; 


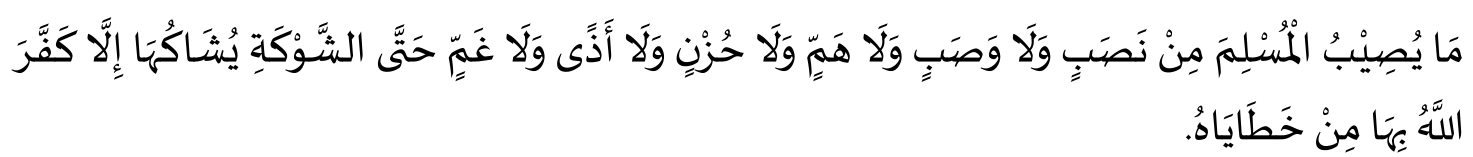

Tidaklah seorang muslim ditimpa; kelelahan, penyakit, kesusahan, kesedihan, gangguan, kegelisahan, hingga duri yang menusuknya, kecuali Allah akan mengampuni dosa-dosanya dengan (sebab) tersebut. (Al-Bukhari, 1436: 5642)

Dari paparan di atas dapat disimpulkan bahwa warga Kepatihan Jember telah mengimplemantasikan hadis-hadis sabar dalam menghadapi bencana banjir yang terjadi di bulan Februari 2021.

\section{KESIMPULAN}

Berdasarkan pemaparan dalam pembahasan dapat diambil kesimpulan sebagai berikut:

1. Terdapat beberapa redaksi hadis tentang sabar, di antaranya adalah: hadis dari Abu Malik Al-Asy'ari, hadis dari Anas, hadis dari 'Ubadah bin Ash-Shamit, hadis dari Abu Sa'id AlKhudri, dan hadis dari Shuhaib radhiyallahu 'anhum.

2. Di Kepatihan Jember terdapat $32 \mathrm{KK}$ yang terdampak banjir, yang parah ada 8 rumah, salah satunya ada 1 rumah yang kamar belakang dan dapurnya ambrol. Sejak tahun 1993 hingga 2021 telah terjadi 5 kali banjir dan banjir di bulan Februari 2021 merupakan banjir yang terbesar.

3. Warga Kepatihan Jember telah mengimplemantasikan hadis-hadis sabar dalam menghadapi bencana banjir yang terjadi di bulan Februari 2021. 
p-ISSN: $2339-2630$

e-ISSN: $2477-8001$

\section{E. DAFTAR PUSTAKA}

Al-Qur'an al-Karim.

Al-Bukhari, Muhammad bin Isma'il. Shahih al-Bukhari. Cet. I; Kairo: Maktabah al-Imam Muslim, $1436 \mathrm{H}$.

Al-Ghurasi, Muhammad Shalih. Intisari Minhajul Qashidin, terj. Muhammad Suhadi. Solo: Aqwan, 2010.

Al-Jauziyah, Ibnu Qayyim. 'Uddah al-Shabirin wa Dzakhirah al-Syakirin. Beirut: Dar al-Kitab al-`Arabi, 1426.

Al-Mahalli, Jalaluddin Muhammad bin Ahmad bin Muhammad dan Jalaluddin 'Abdurrahman bin Abu Bakar As-Suyuthi. Tafsir al-Jalalain. Riyadh: Dar al-Salam li al-Nasyr wa alTauzi', 1422.

Moleong, J. Lexy. Metodologi Penelitian Kualitatif. Bandung: Remaja Rosda Karya, 2005.

Muhajir, Noeng. Metode Penelitian Kualitatif. Yogyakarta: Rake Sarasin, 2003.

Al-Naisaburi, Abu Husain Muslim bin Hajjaj bin Muslim al-Qusyairi. Shahih Muslim. Cet. I; Kairo: Al-Dar al-`Alamiyyah, 1437 H.

Al-Nasa'i, Abu 'Abdirrahman Ahmad bin Syu'aib. Sunan al-Nasa'i: Al-Mujtaba. Cet. I; Damaskus: Muassasah al-Risalah al-Nasyirun, 1436 H.

Al-Qazwini, Abu 'Abdillah Muhammad bin Yazid Ibn Majah. Sunan Ibn Majah. Cet. I; Kairo: Al-Dar al-'Alamiyyah, $1439 \mathrm{H}$.

Parwanto, Wendi. "Teologi Bencana Perspektif Hadis: Mendiskusikan antara yang Menghujat dan yang Moderat.” Al-Bukhari: Jurnal Ilmu Hadis. Vol. 2, No. 1, 2019.

Rahardjo, Mudjia. Mengenal Lebih Jauh Tentang Studi Kasus. Malang: Materi kuliah Metodelogi Penelitian PPs UIN Maliki Malang, 2012.

Salewe, M. Idman. “Sabar Dalam Hadis.” Al-Bukhari: Jurnal Ilmu Hadis. Vol. 1, No. 1, 2018.

Al-Sa'di, 'Abdurrahman bin Nashir. 99 Hadis Pedoman Hidup Muslim, terj. M. Alwan. Solo: Fatiha Publishing, 2016.

Sugiono. Metode Penelitian Kuantitatif, Kualitatif dan $R \&$ D. Bandung: Alfabeta, 2008. 
Suprayogo, Imam, et. al. Metodologi Sosial Agama. Bandung: Remaja Rosda Karya, 2003.

Suryadilaga, Muhammad Alfatih. "Pemahaman Hadis Tentang Bencana (Sebuah Kajian Teologis Terhadap Hadis-hadis Tentang Bencana)." Jurnal Intervensi Psikologi. Vol. 4, No. 2, 2012.

Suyanto, Bagong, et. al. Metode Penelitian Sosial: Berbagai Alternatif Pendekatan. Jakarta: Kencana, 2007.

Al-Tirmidzi, Abu 'Isa Muhammad bin 'Isa bin Saurah. Al-Jami' al-Shahih: Sunan al-Tirmidzi. Cet. I; Kairo: Al-Dar al-'Alamiyyah, 1439 H.

Ujung, Arco Triady, Arief Laila Nugraha dan Hana Sugiastu Firdaus. "Kajian Pemetaan Risiko Bencana Banjir Kota Semarang Dengan Menggunakan Sistem Informasi Geografis.” Jurnal Geodesi Undip. Vol. 8, No. 4, 2019.

Al-'Utsaimin, Muhammad bin Shalih. Syarh Tsalatsah al-Ushul. Beirut: Dar al-Kitab al'Ilmiyyah, 1427.

Uyun, Qurotul dan Rumiani. "Sabar dan Shalat Sebagai Model Untuk Meningkatkan Resiliensi di Daerah Bencana Yogyakarta.” Jurnal Intervensi Psikologi. Vol. 4, No. 2, 2012. 